WellBeing International

WBI Studies Repository

1986

\title{
The Case for Intensive Farming of Food Animals
}

Stanley E. Curtis

University of Illinois at Urbana-Champaign

Follow this and additional works at: https://www.wellbeingintlstudiesrepository.org/acwp_faafp

Part of the Agribusiness Commons, Animal Studies Commons, and the Business Law, Public Responsibility, and Ethics Commons

\section{Recommended Citation}

Curtis, S.E. (1986). The case for intensive farming of food animals. In M.W. Fox \& L.D. Mickley (Eds.), Advances in animal welfare science $1986 / 87$ (pp. 245-255). Washington, DC: The Humane Society of the United States.

This material is brought to you for free and open access by WellBeing International. It has been accepted for inclusion by an authorized administrator of the WBI Studies Repository. For more information, please contact wbisr-info@wellbeingintl.org.

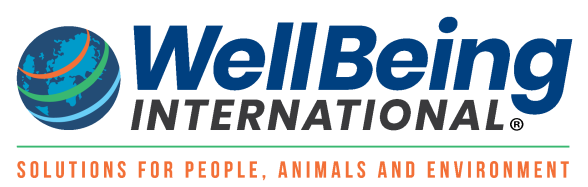




\section{THE CASE FOR INTENSIVE FARMING OF FOOD ANIMALS ${ }^{1}$}

\section{Stanley E. Curtis ${ }^{2}$}

\section{Introduction}

Great strides have been made in recent decades in applying principles of biology and engineering in animal agriculture. Sophisticated animal production systems have been developed in response to numerous pressures. But many technological riddles still remain. Fortunately, our seemingly insatiable curiosity about the nature of things and our inexorable drive to apply what we know guarantee both our continuing search for new knowledge about relations between animals and their environments, and our rapid use of that knowledge to upgrade and fine-tune animal production systems for the benefit of animals, the consuming public, and the agricultural industries alike.

Ecology has always been at the heart of animal farming. After the glaciers receded and crop production was established, animal production ascended. The animals recruited for domestication by early farmers - the same species farmers all over the world raise nowadays-differed from their cousins that have been left in the wild in that those domesticated were adaptable to a wider range of environments. Agricultural animals are relatively unfinicky and tolerant. During the millennia when farm animals were kept in the natural environment, or at best shielded poorly from climatic rigors, the relative ease with which the animals appeared to adapt to their surroundings led husbandmen to give the environment a low spot in the hierarchy of production factors.

The situation has changed greatly during the last 40 years. The advent of widespread intensivism in animal agriculture--together with ever smaller profit margins and our relentless search for ways to increase food-production efficiency - increased the relative significance of animal-environmental relations. Now, in addition to paying close attention to the nutritional and health-care needs of the animals and to increasing the genetic fit of the animals to the environment, we try to meet the animals' needs by modifying the several facets of their surroundings. Of course, all of these efforts have been made possible by the increase in our knowledge base that has resulted from experimental research on animals

It is not likely that animal farms are today as we remember they were yesterday. It is likely that they never were. Our notions of how things used 
passage of time. Be that as it may, to appreciate the modern, intensive systems of animal agriculture that have sprung up in many parts of the world, we must consider them in the context of the human cultures in which they arose.

Our world is still a hungry place. At the same time, the number of people worldwide who grow food for themselves continues to dwindle. Most U.S. citizens have never set foot on a farm or harvested one mouthful - let alone a lifetime's worth-of daily bread. Yet our farmlands and climates and our agricultural and food industries are this nation's ultimate resources. By increasing productivity, our farmers and the scientific and business endeavors that support our nation's food production, processing, and distribution have proved to be able and reliable husbands of these precious resources. But make no mistake: The challenge to increase food production in step with increasing demands is a huge one. It requires managing numerous elements of nature which are recalcitrant at best, while coping with others which are manageable or unpredictable, or both. Our agribusinesses have made the task simple; plenty of safe, wholesome, inexpensive food is available in our groceries every day. Again, make no mistake: Making this so has not been a simple task. It is incumbent upon severe critics of American animal agriculture to recognize and appreciate this and to make their retrospective judgments accordingly.

\section{Stress}

Before discussing intensive management of food animals in the United States, a few words should be said about stress in general. Any animal, in the wild or on a farm, is usually responding to several stressors at once. Stress is the rule, not the exception. And nature has endowed animals with a marvelous array of reactions to stress. The animal must maintain a steady bodily state despite fluctuating external conditions. By means of dozens of negative-feedback control loops, the animal tries to regulate within narrow limits the environment in which its individual cells reside and operate.

An environmental adaptation is any functional, structural, or behavioral trait that favors an animal's survival or reproduction in a given environment. A stress is any environmental situation that provokes an adaptive response. Stress can occur when an animal's environment changes so as to trigger some homeokinetic response (as when environmental temperature falls below some critical point) or when the animal itself changes in relation to its surroundings (as when shearing reduces a sheep's cold tolerance).

The scientific literature contains reports of hundreds of experiments purported to measure the environmental adaptability of agricultural animals. It is a relatively simple task to subject experimental animals to a controlled stressor and measure a resultant change in some physiological, immunological, anatomical, or psychological characteristic. But an objective index of stress in terms of animal health, productivity, and overall well-being has been elusive.

Still, it is a fundamental tenet of modern animal agriculture that environmental stress generally alters animal performance. The stress provokes the animals to react, and this reaction can influence the partition of resources amoung maintenance, reproductive, and productive processes in at least five 
ways (Curtis 1983). (1) The reaction might alter internal functions. Many bodily functions participate in productive and reproductive processes as well as in reactions to stress, which are of higher priority. (2) The reaction might divert nutrients. When an animal responds to stress, it in effect diverts nutrients from productive and reproductive processes to uses in higher priority maintenance processes. (3) The reaction might reduce productivity directly. The animal's response sometimes comprises an intentional reduction in productive processes in order to free some nutrients for maintenance use. (4) The reaction might increase variability in productive performance. Individual animals differ from one another in the ways they respond to the same stressor. The complements of mechanisms used often differ in the energy expenditure they require, so the amount of metabolizable-energy expenditure which must be diverted from productive processes to maintenance differs. The result is that the amount of variation in individual performance tends to be directly related with the environmental adversity to which a group of animals is subjected. (5) The reaction might alter disease resistance. Because an animal's reaction to stress can affect disease resistance, that stress reaction can influence the frequency and severity of infectious diseases.

That stress in agricultural animals must be optimized in terms of both animal welfare and economic ramifications should be obvious from these general relationships. This is an important issue, and it will pervade all that follows.

\section{Intensive Farming of Food Animals}

Hundreds of millions of Americans must have food but choose not to grow it for themselves. Food production is a business and subject to the same economic forces as any business (Halcrow 1980). The chances of a turnaround in the trend to fewer, larger, more intensive animal farms are akin to those of a return to mom-and-pop grocery stores in the residential areas of every city and an independent fast-food restaurant on the main street of every town.

Intensive dairy, livestock, and poultry farms came on the scene soon after World War II. The movement of agricultural animals from dirt lots and pastures to confinement facilities accelerated markedly during the 1950s in the poultry and dairy industries and the $1960 \mathrm{~s}$ in livestock production. It continues to this day. The most important reason for this did not revolve around the well-being of the animals. Admittedly, although there have been significant side-benefits of intensivism for the animals, there have been new problems, too (Curtis 1983).

One major force leading to intensivism in animal agriculture had to do with responsible land management. Rearing animals extensively requires tremendous acreages, and in many parts of the United States it not only constitutes unsound stewardship of the soil, but it has proved economically unfeasible as well.

Another critical factor was labor. With the family farm goes the force of cheap workers upon which this kind of farming was based. Also, animal caretaking is a seven-day-a-week job, so to attain a living standard similar to 
that of society as a whole, outside help was needed. Today's poultry, livestock, and dairy producers increasingly need to hire workers from the general labor pool to do chores formerly assigned to family members. Of course, prevailing wages must be offered if workers are to be attracted. Despite relatively high rates of unemployment in many rural communities in recent years, the farmer often has had to provide unusual incentives to employees, because the work is hard, and in some respects, unappealing. Thus, animal producers have had to expand and specialize their operations to the extents necessary to justify increased outlays for hired help.

A third factor has been animal waste. Farm animals produce tremendous amounts of feces and urine. For example, one hog puts out as much waste as three adult humans. Of course, the magnitude of the waste-management task rises in parallel with the size of operation. Because of the keen interest in environmental protection over the past two decades, regulations have been put in place which in effect preclude animal production on many of the hills and in many of the valleys these animals roamed in days past. For practical purposes, waste containment is achievable only with a confinementproduction facility.

Land, labor, and waste-these have been the principal socioeconomic forces behind the widespread adoption of intensive animal-production systems. The changes that have resulted from these forces have had impacts on the animals' welfare. At this point, let us mention those changes that have been beneficial for the creatures. For one thing, seasonal production cycles have been dampened considerably. It is easier to manage newly born or hatched animals - and juveniles and adults, too, for that matter-the year around in houses than in either natural surroundings or rudimentary artificial shelters typical of extensive production. This has been good for the animals. And the resultant changes in dairy, poultry, and livestock marketing increased economic efficiencies in food production, processing, and distribution. The ultimate beneficiaries of these efficiencies in our free-enterprise economy are the consumers of food products of animal origin.

More pluses have to do with biological management, with the animal's life per se. (1) Providing steady supplies of a well-balanced diet and sanitary water is easier in confinement than on range. (2) Predation of young and small animals by wild and feral carnivores is a tremendous problem in many parts of the United States. Intensive animal facilities such as sheep folds have been used to foil this aspect of the web of life since biblical times. (3) The perforated floors commonly used in animal facilities separate the beasts and birds from their own excreta, thus preventing them from practicing some unhygienic, obnoxious habits such as coprophagy and wallowing in their own excrement. Because enteric infections are major causes of disease and even death in all species of farm animals, the perforated floor improved the living conditions of these creatures greatly. (4) Caretakers can observe individual animals more thoroughly when they are close at hand, held singly, or in small groups. Injuries and disease can be detected more readily and remedial measures implemented more easily as a result. 
Interestingly, despite technological changes, managers of large, intensive animal farms still consider sound animal care the keystone of profitability in animal production. Can anything else be imagined by anybody? Excellent animal husbandry is the sine qua non of successful animal production.

The advent of larger units also made it possible to upgrade management quality. On many farms, animal production is no longer a sideline activity or one of several enterprises competing for the manager's attention. More and more, managers of animal-production operations are multitalented professionals who devote all of their time to a single species. Demand for well-educated and -trained managers has led to the establishment of special curricula in intensive animal production.

Finally, with increasing size of operation come economies of purchasing and marketing in large lots, with more or less continuous flow (Halcrow 1980). While this generally enhances the profitability of an individual enterprise, again consumers of foods of animal origin are the ultimate beneficiaries in our kind of economy.

In agriculture, it is not sufficient to be interested only in physiological, behavioral, immunological, and anatomical indices of animals' environmental adaptability. The next question is: How much decrement in production is associated with residing in a particular environment? To learn the quantitative effects of a given environment on animal performance, we still must measure the productive traits themselves. An animal exhibiting obvious reaction to stress, as mentioned above, is generally assumed to be having depressed performance. But the performance loss may be reversible only by a modification of the environment that cannot be repaid in terms of increased animal productivity. Further, visible strain in an animal signifies that it is trying to compensate for an environmental impingement. These attempts might succeed, and they might interfere with performance only slightly. Of course, the question remains as to whether the stresses imposed by a certain production system comprise an unacceptable environment in terms of the animals' overall welfare, a point to be expanded upon later.

\section{Abuse, Neglect, and Deprivation}

Animal production resembles other professions in that there are (in terms of humane treatment) good animal farmers and poor ones. When critics of animal farms cite examples of cruelty to animals, they are referring to farms run by poor producers. Inhumane treatment leads to unhealthy, unproductive animals, and consequently, financial losses. Poor stockmen are among the first animal farmers to go out of business in times of economic crisis.

It has been suggested that any suffering an animal experiences at the hands of a farmer falls into one of three categories: abuse, neglect, or deprivation (Ewbank 1981). Abuse refers to obvious, active cruelty, such as beating an animal with a stick. Neglect is obvious, passive cruelty; for example, confining an animal and then not providing it one or more vital resources, such as food or water. Everyone would agree that abuse and neglect are cruel, and state and federal legislation outlawing both was passed many years 
ago. Progressive animal producers neither condone nor encourage such cruelty, and any representation to the contrary comprises a calumny. Further, abuse and neglect constitute or lead to severe stress and thus are clearly counterproductive; their practice by farmers would be just as clearly irrational.

Deprivation is the most subtle form of cruelty, and thus the most difficult to assess. It involves the denial of relatively less vital resources, the actual requirements for which mostly have yet to be established. Whether or not farm animals in certain living situations in intensive production systems are suffering from deprivation is a major issue being discussed by humane activists, farmers, and scientists. If so, economical and practically feasible means of alleviating the deprivation will need to be discovered and developed for adoption by farmers. While it might be tempting to speculate anthropomorphically as to the stress perceived by animals when they are prevented by the nature of the environment in which they reside from performing some specific behavior, both humane and economic aspects of environmental design and management are better served when the scientific approach to needs identification and fulfillment is taken.

\section{Needs: Physiological, Safety, and Behavioral}

It is axiomatic that, when an animals' needs are not being met, its welfare is more or less jeopardized. But here again it must be remembered-and this idea also will be expanded upon later - that a particular welfare decrement does not necessarily place the animal in an ethically unacceptable environment; perhaps the animal simply experiences less-but still an ethically acceptable amount - of well-being.

In any case, it has been suggested that agricultural animals have a hierarchy of needs along the lines of Abraham Maslow's scheme for humans, and that animals' basic needs are being met in most intensive production systems (Curtis 1984). First and most basic are farm animals' physiological needs; for feed, physical and biological elements of the environment, and health care. These are already relatively well understood and fulfilled.

Intermediate are the animals' safety needs. Although the needs to be protected from harmful environmental elements are important, these safety needs are tended somewhat less rigorously than are the physiological needs. Weather accidents,predation, and poorly designed, manufactured, and operated equipment and facilities still exact reducible tolls in terms of both animal welfare and financial profits (Curtis 1984).

Last in the hierarchy are the animals' behavioral needs. The question among most scientists is: Is there reasonable evidence supporting the existence of any behavioral need in any agricultural animal? Indeed, no such need has been established, although many scientists believe that they well might exist, however difficult they may be to elucidate (Hughes 1980). Of course, fundamental to assessing welfare in a farm animal are answers to two questions, the second of which is proving to be exceedingly difficult to answer: (1) Does the animal have subjective feelings? (2) What indicators reveal any such feelings? (Duncan and Dawkins 1983). Knowledge of animals' 
mental activities can be gained only via indirect experimental evidence at this time, hence any conclusions must be considered tentative.

\section{Assessing Welfare in Farm Animals}

Attempts to quantitatively evaluate suffering or its antithesis, welfare, in animals residing in various farm environments have proved futile so far (UFAW 1979; Brown 1980; Bessei 1982; Curtis 1982; Baxter et al. 1983; Duncan and Dawkins 1983; Smidt 1983a; Tarrant 1984; Moberg 1985; Wiepkema 1985). There is a consensus that the welfare of farm animals eventually will be best assessed by an integrated system of indicators from four categories: (1) reproductive and productive performance, (2) pathological and immunological traits, (3) physiological and biochemical characteristics, and (4) behavioral patterns (Duncan 1981; Curtis 1982; Smidt 1983b). At present, potential pitfalls notwithstanding (Duncan and Dawkins 1983), health, reproductive, and productive traits continue to be the most readily measurable, most practically useful indicators of fit between agricultural animals and the environments in which they reside (Curtis 1982).

\section{Welfare Plateau, Economics, and Production Environments}

On any animal farm, achieving the highest level of animal welfare possible, consistently, is still a vague exercise. It most likely will be so for several years. C.D. Hardwick formulated the idea that an ethically acceptable level of animal welfare exists over a range of conditions provided by a variety of agricultural production systems, not only in one ideal set of circumstances (Duncan 1978). This acceptable range of environments, Hardwick said, comprises a "welfare plateau" (figure 1). The word, "plateau," may be misleading; in the acceptable range, with improvements in environment, the animals' total welfare increases, too. Indeed, increasing welfare is the basis for identifying environmental "improvement." But Hardwick's notion was this: Any point on the welfare plateau is ethically acceptable in terms of animal welfare. In other words, on the welfare plateau, a relatively small environmental change might improve subtly an animal's overall well-being, but anywhere on the welfare plateau the animal is as free of suffering as possible.

The concept of the welfare plateau is profoundly relevant to discussions of environmental design for animal farms. At the lower limit of the welfare plateau might stand one or more production systems that are marginally acceptable in terms of the animal welfare they engender, while beyond this gray zone stand systems that more or less fail to support the animals' needs sufficiently well to be considered ethically acceptable.

The farmer as businessperson recognizes that, already in the zone of marginally acceptable production systems, the law of diminishing returns (Halcrow 1980) has ensued; returns to investments in environmental improvements are not sufficient to pay for the improvements. In contrast to this, in the range of unacceptable environments, small environmental improvements result in returns that are more than adequate to pay for the improvements. Thus, there is the logical tendency for the production systems adopted most 


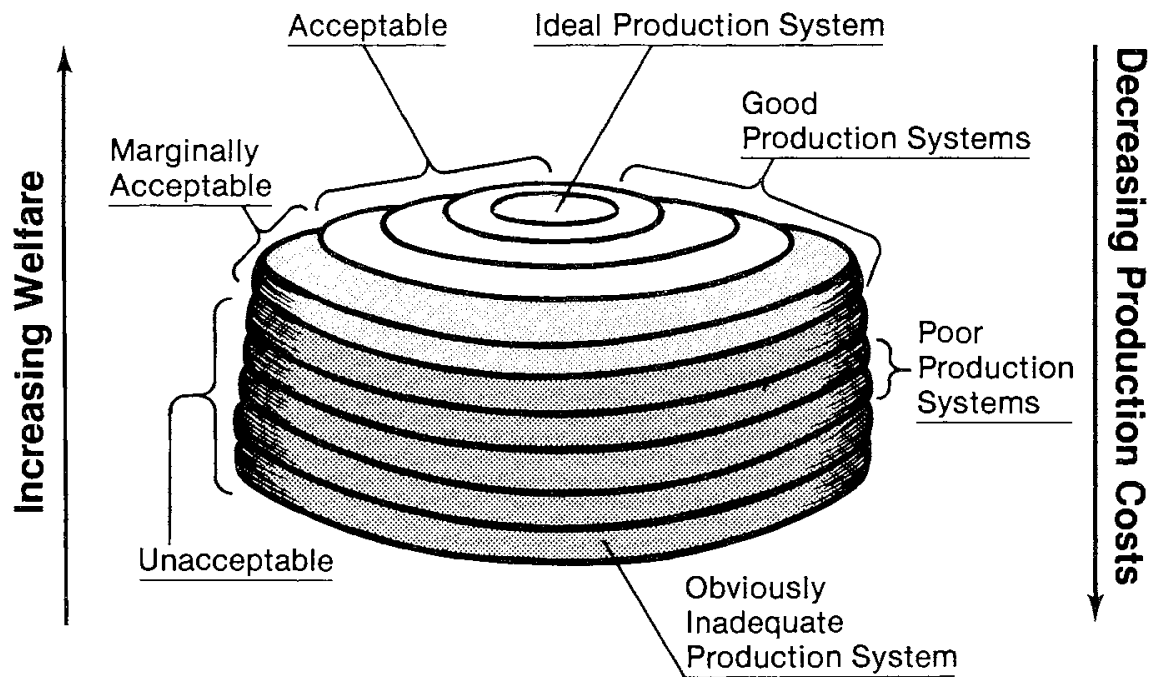

\section{Welfare Plateau}

Figure 1. Scheme relating respective animal production systems to the animal welfare they engender. Scheme incorporates C.D. Hardwick's idea of a "welfare plateau" (modified after Duncan 1978)

widely to be located at the upper end of the marginally acceptable zone and the lower end of the acceptable zone. Said another way: The shape of the HardwickDuncan scheme is determined mainly by (1) decreasing frank suffering by the animals as the environment is improved within the unacceptable zone; (2) flexion in the marginally acceptable range, where the law of diminishing returns sets in; and (3) inadequate returns to investment on the welfare plateau, throughout which (a) frank suffering is minimal and (b) those small additional returns that do occur owe to increased animal well-being alone.

The animal producer is thus faced with the necessity of compromising welfare for profit. As a humane person, the producer strives to provide the animals an existence as free of suffering as possible. This limits the possibilities to the upper region of the marginally acceptable range or the welfare plateau itself. As a businessperson, the producer strives to adopt the production system that will be economically optimal for prevailing conditions. In view of the law of diminishing returns, this latter constraint tends to locate adoptable systems in the upper region of the marginally acceptable range or in the lower part of the welfare plateau. To locate nearer the humane ideal would be an unwise business decision. Still, as long as the system adopted lies in or very near the acceptable zone, the producer's ethical obligations have been satisfied 


\section{Summary and Conclusions}

Alas, farmers face an animal-welfare dilemma. They must decide on animalproduction systems while constrained by humane concerns - both their own as well as those of the general citizenry-on one hand and by the realities of doing business in a free-enterprise milieu on the other. And the dilemma will be resoluble only if and when we know much more than we now know about animal suffering and thus about animal well-being. The question is not whether animals have feelings; there is general agreement up and down the line that they do. The question is: How does the animal feel, living in this production system or that? Ian Duncan and Marian Dawkins (1983) believe that there are "... indicators that with careful experimentation we may be able to accumulate indirect evidence about animals' subjective feelings. This should be our ultimate aim. There are many problems but they are not insurmountable."

How can these problems be surmounted? How will it come to pass that we learn once and for all whether certain production systems cause farm animals to suffer? How will economically feasible, more socially acceptable systems of farm-animal production be discovered and developed? The answer: We can learn these things only from research.

The time is ripe for humane activists to support in all ways possible bona fide scientific investigations of farm animal welfare. This suggestion is not heretical, naive, or ridiculous. My reasoning follows, in the form of a brief recapitulation and juxtaposition of earlier points with a couple of new ones, together with pragmatic analysis and synthesis.

1. Consumer demand for human foods of animal origin is strong, and it will continue to be so for decades. The vast majority of consumers decide whether or not to eat these foods on the bases of nutritional factors, convenience, and flavor, not on the basis of ethical questions. It is folly to hope that animal farms will disappear from the U.S. scene. Those of us who want farm animals to experience as little suffering and as much wellbeing as possible ought to do what we can to ensure that these animals' needs and feelings are understood, and that the needs are fulfilled, the feelings protected.

2. Food-animal production is a business. As such, it is constrained by economic factors.

3. Society - including animal producers - requires that food animals not be caused to suffer in any way. Therefore, food animal production is also constrained by humane factors.

4. Economic and humane factors do not always work in tandem. Compromise between humane and economic constraints is inevitably necessary in terms of animal-production-system design. This compromise occurs at the juncture of the welfare plateau and the range of marginally acceptable production systems.

5. Animal agriculture quickly adopts appropriate technologies, especially when the benefit/cost ratio is favorable.

6. Animal producers are at least as humane as members of society in general. Any representation to the contrary comprises a calumny. 
7. If animal producers have adopted inhumane production technologies, it has been because they and those who advise them have been ignorant Any such ignorance owes to lack of scientific evidence, not lack of concern for the animals' general well-being.

8. Those of us who care about animals and want to try to improve the welfare of food animals ought to do everything we can to learn more about what these animals need and how they feel. At the same time, we can be searching for improvements in terms of production equipment and facilities and husbandry systems designed to fulfill the animals' needs and support favorable feelings. Basic and applied research along these lines deserves the complete support of all who want to engender the highest level of welfare possible in food animals.

\section{Endnotes}

${ }^{1}$ Paper presented at the national conference, "Animals and Humans: Ethical Perspectives," Moorhead State University, Moorhead, MN, April 21-23, 1986

2 Professor, University of Illinois at Urbana-Champaign, College of Agriculture, Department of Animal Sciences, 126 Animal Sciences Laboratory, 1207 W. Gregory Dr, Urbana, IL 61801.

\section{References}

Baxter, SH, Baxter, MR and MacCormack, JA. eds. 1983. Farm Animal Housing and Welfare Boston, MA: Martinus Nijhoff Publishers.

Bessei, W. ed. 1982. Disturbed Behaviour in Farm Animals. Stuttgart, FRG: Verlag Eugen Ulmer

Brown, PL. ed. 1980. Proc. First European Conf. on the Protection of Farm Animals. Anim. Reg. Stud. 3(1,2): 1174.

Curtis, SE. 1982. Measurement of stress in animals. In: Woods, W. ed. Proc. Symp. Management of Food Producing Animals. Vol I. West Lafayette, IN: Purdue Univ.

-. 1983. Environmental Management in Animal Agriculture. Ames, IA: Iowa State University Press.

-. 1985. What constitutes well-being? In: Moberg, GP.ed. Animal Stress. Bethesda, MD: American Physiological Society.

Duncan, IJ. 1978. An overall assessment of poultry welfare. In: Sorensen, LY. ed. Proc. First Danish Seminar on Poultry Welfare in Egglaying Cages. Copenhagen, Denmark: National Committee on Poultry and Eggs.

-. 1981. Animal rights-animal welfare: A scientist's assessment. Poul. Sci. 60(3): 489-99.

Duncan, IJ and Dawkins, MS. 1983. The problem of assessing "well-being" and "suffering" in farm animals. In: Smidt, D. ed. Indicators Relevant to Farm Animal Welfare. Boston, MA: Martinus Nijhoff Publishers.

Ewbank, R. 1981. Alternatives: Definitions and doubts. In: Alternatives to Intensive Husbandry Systems. Potters Bar, United Kingdom: Universities Federation for Animal Welfare.

Halcrow, HG. 1980. Economics of Agriculture. New York: McGraw-Hill Book Co.

Hughes, BO. 1980. The assessment of behavioural needs. In: Moss, R. ed. The Laving Hen and Its Environment. Boston, MA: Martinus Nijhoff Publishers.

Moberg, GP. ed. 1985. Animal Stress. Bethesda, MD: American Physiological Society.

Smidt, D. ed. 1983a. Indicators Relevant to Farm Animal Welfare. Boston, MA: Martinus Nijhoff Publishers.

- 1983b. Advantages and problems of using integrated systems of indicators as compared to single traits. In: Smidt, D. ed. Indicators Relevant to Farm Animal Welfare. Boston, MA Martinus Nijhoff Publishers. 
Tarrant, PV. ed. 1984. Evaluation Report 1979-83, Farm Animal Welfare Programme. EUR918EN. Luxembourg, LX: Commission of the European Communities.

UFAW (Universities Federation for Animal Welfare). 1979. The Welfare of the Food Antmals. Potters Bar, UK: Universities Federation for Animal Welfare.

Wiepkema, PR. 1985. Abnormal behaviours in farm animals: Ethological implications. Neth. J. ZOO. 35(1,2): 27999 . 